\title{
Treatment choices in metastatic colorectal cancer according to sidedness and RAS/BRAF status: a national survey by the Brazilian Gastrointestinal Tumors Group (GTG)
}

Opções de tratamento no câncer colorretal metastático segundo a lateralidade e o status RAS/BRAF: uma pesquisa nacional do Grupo Brasileiro de Tumores Gastrointestinais (GTG)

Renata D'Alpino Peixoto ${ }^{1,2}$, Rachel P Riechelmann ${ }^{1,3}$, Gabriel Prolla1,4, Rui F. Weschenfelder ${ }^{1,5}$, Gustavo dos Santos Fernandes ${ }^{1,6}$, Guilherme S Pereira ${ }^{1,7}$, Maria de Lourdes de-Oliveira ${ }^{1,8}$, Juliana F Rego ${ }^{1,9}$, Duilio R Rocha-Filho ${ }^{1,10}$, Anelisa K. Coutinho ${ }^{1,11}$.

\begin{abstract}
Objectives: Tumor sidedness and RAS/BRAF status have changed the treatment landscape of metastatic colorectal cancer (mCRC). This study was performed to understand the first line choices of Brazilian oncologists for patients with mCRC, especially in the emergent context of tumor sidedness and RAS/BRAFV600E status. Methods: This was a cross-sectional electronic survey composed of six questions sent to Brazilian medical oncologists through social media. The survey instrument collected demographic data of participants and assessed current practices in terms of first-line treatment choices for fit patients with mCRC. Participants with at least $50 \%$ of their clinical practice dedicated to patients with $\mathrm{Gl}$ malignancies were deemed Gl specialists. Results: The survey was completed by 239 medical oncologists from across the country. Most oncologists were male (59\%) and were in oncology practice for less than 10 years (62.2\%). Only 20.9\% of the participants were specialists in Gl tumors. For left-sided, wild-type (wt) RAS/wt-BRAFV600E mCRC, most oncologists (82\%) chose first line chemotherapy (CT) + anti-EGFR therapy, with 53.6\% of them preferring FOLFIRI as the CT backbone. Meanwhile, for right-sided, wt-RAS/wt-BRAFV600E mCRC, the majority (70.7\%) would offer CT + bevacizumab (53.9\% with FOLFOX). For mutated-RAS MCRC, most oncologists decided for FOLFOX + bevacizumab (51.9\%). Subgroup analyses revealed statistically significant differences for therapeutic choices in first line for left-sided wt-RAS/wt-BRAFV600E mCRC: female oncologists prefer FOLFOX as CT backbone ( $p=0.004)$ and in right-sided wt-RAS/wt-BRAFV600E $\mathrm{mCRC}, \mathrm{Gl}$ cancer specialists more often use FOLFOXIRI and bevacizumab (18 vs $7.9 \% ; p=0.001$ ). Conclusion: Our survey indicates that tumor sidedness influences the choice of both $\mathrm{CT}$ backbone and monoclonal antibody in unresectable wt-RAS mCRC. In addition, oncologists' gender and percentage of time dedicated to treat Gl cancers also impacted on therapeutic choices for mCRC in Brazil.
\end{abstract}

Keywords: Colorectal neoplasms; Surveys and questionnaires; Antineoplastic agentes.

\footnotetext{
1. Grupo Brasileiro de Tumores Gastrointestinais, GTG, São Paulo, SP, Brazil.

2. Hospital Alemão Oswaldo Cruz, Oncologia, São Paulo, SP, Brazil.

3. AC Camargo Cancer Center, Oncologia, São Paulo, SP, Brazil.

4. Hospital São Lucas da PUC, Oncologia, Porto Alegre, RS, Brazil.

5, Hospital Moinhos de Vento, Oncologia, Porto Alegre, RS, Brazil.

6. Hospital Sírio Libanês, Oncologia, Brasília, DF, Brazil.

7. Centro de Oncologia do Paraná, Oncologia, Curitiba, PR, Brazil.

8. Oncologia D'Or, Oncologia, Rio de Janeiro, RJ, Brazil.

9. Hospital Universitário Onofre Lopes, Oncologia, Natal, RN, Brazil.

10. Fujiday, Oncologia, Fortaleza, CE, Brazil.

11. Clínica AMO, Oncologia, Salvador, BA, Brazil.

Financial support: none to declare.

Conflicts of interest: The authors declare no conflict of interest relevant to this manuscript.

Correspondence author: Renata D'Alpino Peixoto. Grupo Brasileiro de Tumores Gastrointestinais, GTG - São Paulo.

Rua Treze de Maio, 1815, Bela Vista, São Paulo, SP, Brazil. Zip code: 01327-001.

E-mail: renatadalpino@gmail.com
}

Received on: February 20, 2018 | Accepted on: March 21, 2018

DOI: $10.5935 / 2526-8732.20190021$ 


\section{RESUMO}

Objetivos: A lateralidade tumoral e o status RAS/BRAF mudaram o cenário de tratamento do câncer colorretal metastático (CCRm). Este estudo foi realizado para entender as primeiras linhas de escolha de oncologistas brasileiros para pacientes com CCRm, especialmente no contexto emergente de lateralidade tumoral e o status RAS/BRAFV600E. Métodos: Tratase de uma pesquisa eletrônica transversal, composta por seis questões encaminhadas aos médicos oncologistas brasileiros por meio das mídias sociais. $\mathrm{O}$ instrumento de pesquisa coletou dados demográficos dos participantes e avaliou as práticas atuais em termos de opções de tratamento de primeira linha para pacientes em tratamento com CCRm. Participantes com pelo menos $50 \%$ de sua prática clínica dedicada a pacientes com malignidades gastrointestinais foram considerados especialistas gastrointestinais (GI). Resultados: A pesquisa foi preenchida por 239 médicos oncologistas de todo o país. A maioria dos oncologistas era do sexo masculino (59\%) e praticava oncologia há menos de 10 anos (62,2\%). Apenas 20,9\% dos participantes eram especialistas em tumores GI. Do lado esquerdo, o CCRm do tipo selvagem (wt) RAS/wt-BRAFV600E, a maioria dos oncologistas (82\%) escolheu como primeira linha a quimioterapia (QT) + terapia anti-EGFR, com 53,6\% deles preferindo o FOLFIRI como base da QT. Entretanto, para o CCRm do lado direto, no (wt)-RAS/wt-BRAFV600E, a maioria (70,7\%) oferece QT + bevacizumabe (53,9\% com FOLFOX). Para o CCRm RAS mutado, a maioria dos oncologistas decidiu pelo FOLFOX + bevacizumabe (51,9\%). Análises de subgrupos revelaram diferenças estatisticamente significantes para as escolhas terapêuticas na primeira linha de tratamento do CCRm do lado esquerdo wt-RAS/ wt-BRAFV600E: oncologistas do sexo feminino preferem FOLFOX como base da QT $(p=0,004)$, e no CCRm do lado direito, wt-RAS/wt-BRAFV600E, especialistas em câncer gastrointestinal mais frequentemente usam FOLFOXIRI e bevacizumabe (18 vs 7,9\%; $p=0,001)$. Conclusão: Nossa pesquisa indica que a lateralidade do tumor influencia em ambas a escolha base da QT e do anticorpo monoclonal no CCRm não ressecável do RAS. Além disso, os oncologistas em gênero e porcentagem de tempo dedicados ao tratamento de cânceres gastrointestinais também tiveram impacto nas escolhas terapêuticas para o CCRm no Brasil.

Descritores: Neoplasias colorretais; Pesquisas e questionários; Antineoplásicos.

\section{INTRODUCTION}

According to the World Health Organization, colorectal cancer (CRC) is the third most common cancer worldwide. In 2018, approximately 1.8 million people were diagnosed with this tumor type. ${ }^{1}$ In Brazil, CRC has also a high incidence pattern, with 36.360 new cases estimated in 2019. ${ }^{2}$ It, therefore, occupies the second position in terms of cancer incidence among women and the third among men (excluding non-melanoma skin cancer). ${ }^{2}$ Unfortunately, the 5-year survival rate is less than $15 \%$ for CRC patients with distant metastasis.

CRC originates from the epithelial tissue of the colon, and it may arise either from the right or left the side of the colon, where the splenic flexure is the dividing point. They exhibit differences in blood supply, embryologic development, clinicopathologic characteristics and anatomic features. ${ }^{3}$ There has also been growing evidence that proximal and distal CRC differ, as a continuum, with respect to their biology, microbiota, genomic patterns, therapeutic response and prognosis, with right-sided tumors having an overall worse prognosis. ${ }^{4-8}$

Retrospective analyses from two pivotal first-line

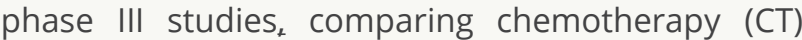
(FOLFIRI or FOLFOX) plus cetuximab versus $C T$ plus bevacizumab, reported improved overall survival (OS) in the cetuximab group for left-sided wildtype (wt) RAS mCRC. ${ }^{6-7}$ In contrast, patients with right-sided wt-RAS tumors appeared to derive more benefit from bevacizumab. In addition, a metaanalysis suggested that tumor location is a predictive marker of the response to anti-EGFR therapy (either cetuximab or panitumumab) in patients with RAS wt $\mathrm{mCRC}{ }^{8}$ Patients with left-sided tumors experience longer OS and greater response rate with $\mathrm{CT}$ plus anti-EGFR, while right-sided tumors were associated with a trend towards better OS with CT plus bevacizumab. ${ }^{8}$ Those findings led most international guidelines to incorporate tumor sidedness into firstline therapeutic decisions for wt-RAS $\mathrm{mCRC}$, where anti-EGFR therapy is recommended only for RAS/wt$B R A F_{V 600 E}$ and left-sided tumors. ${ }^{9-10}$ 
Despite those recommendations, little is known whether such international recommendations have influenced clinical practice in Brazil. The Brazilian Gastrointestinal Tumors Group (GTG) is the leading gastrointestinal (GI) cancer society in the country and has the objective of assisting, promoting, developing and encouraging scientific, technological, cultural, educational and social actions aimed essentially at improving the knowledge of $\mathrm{Gl}$ tumors and related medical sciences. This survey was created by GTG to understand the first line choices of Brazilian oncologists for patients with unresectable $\mathrm{mCRC}$, especially in the emergent context of tumor sidedness and $R A S / B R A F_{V 600 E}$ status. We also aim at exploring differences in therapeutic choices by oncologists according to gender, years in practice and time dedicated to GI practice.

\section{METHODS}

\section{Study Design}

This was a cross-sectional electronic survey composed of six close-ended questions, which was sent to Brazilian medical oncologists and medical oncology groups by social medias such as email, Facebook and/or Whatsapp. The target survey population was medical oncologists who were members of GTG and those working in leading institutions in Brazil that offer cancer treatments. The contact to invite the participation was conducted by the GTG board of directors. The electronic survey was sent to all potential candidates twice within 30 days. The consent to participate in this study was obtained by the acceptance to complete the questionnaire, which guaranteed that all participants' data would be treated anonymously. Given that this was a survey on treatment practices, the study was not submitted to an ethics committee.

The survey instrument assessed current practices in terms of first-line treatment choices for fit patients with $\mathrm{mCRC}$, including left-sided wt-RAS/wt-BRAF $F_{\text {V600E }}$ right-sided wt-RAS/wt-BRAF ${ }_{\text {V600E }}$ and any-side mutated $R A S$, considering that all drugs were available. The instrument also elicited data about years in practice in Medical Oncology, gender and how much of each oncologists' practice was dedicated to GI cancers. Those with at least $50 \%$ of their clinical practice dedicated to patients with GI malignancies were considered specialists. The time estimated to complete the survey was between two to four minutes. The study was funded by the GTG.

\section{Statistical analyses}

The online questionnaire was developed using the Survey Monkey platform. Only fully completed questionnaires were included in the analyses. Descriptive statistics were reported for all responses. Subgroup comparisons were analyzed with $\chi^{2}$ tests for binary variables. A two-tailed $p$-value $<0.05$ was considered statistically significant. A sample size was not formally computed for this study but rather, we aimed to enroll a larger possible sample size to more accurately estimate treatment practices.

\section{RESULTS}

\section{Respondents' characteristics}

The survey was completed during a 30-day period (February $20^{\text {th }}, 2018$ to March $21^{\text {st }}, 2018$ ) by 239 medical oncologists who agreed to participate from across the country. Because the survey was not sent to all individual emails, we could not estimate the response rate but for those who responded, the completion rate was $100 \%$.

The majority of respondents were male (59\%) and were in oncology practice for less than 10 years $(62.2 \%)$ (Figure 1). Among those with more than 30 years of oncology practice, less than $10 \%$ were female. However, women correspond to more than $50 \%$ among those with less than 5 years of practice (Figure 2). The proportion of women in oncology practice significantly increased over time $(p=0.032)$.

Only $20.9 \%$ of the participants were specialists in Gl tumors while $30.5 \%$ treated GI cancer patients for less than $25 \%$ of their practice. In regards to proportion of time dedicated to treat $\mathrm{Gl}$ cancers, there was neither difference between males and females $(p=0.872)$ nor according to years of oncology practice $(p=0.766)$.

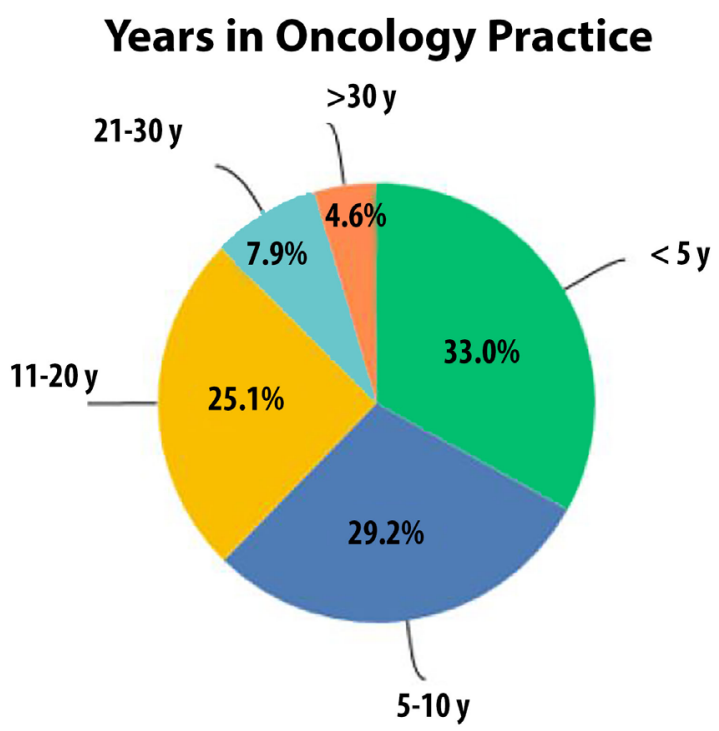

Figure 1. Distribution of oncologists according to years in oncology practice. 


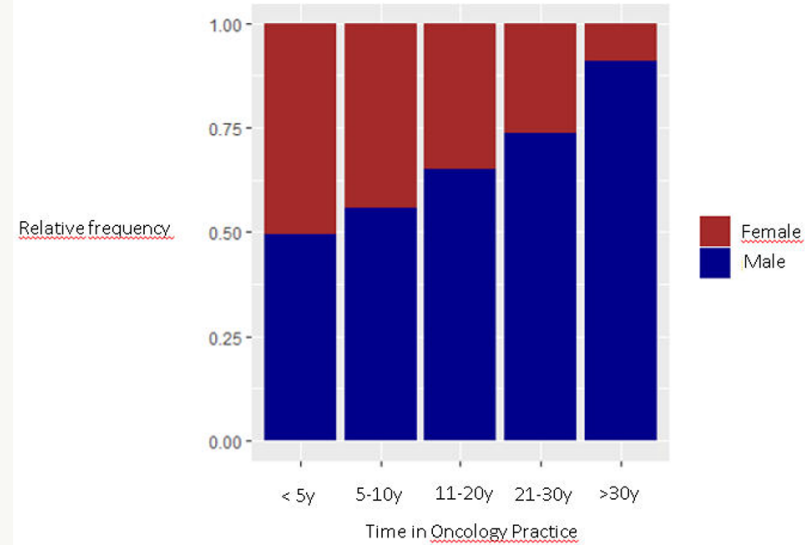

Figure 2. Gender proportion according to time in oncology practice.

\section{Treatment choices according to RAS, BRAF and sidedness}

For left-sided wt-RAS/wt-BRAFV600E mCRC, most oncologists (82\%) chose first line CT + anti-EGFR therapy, with $53.6 \%$ of them preferring FOLFIRI and 46.4\% FOLFOX as the CT backbone (Table 1). For those $18 \%$ who chose CT + bevacizumab, $60.4 \%$ preferred FOLFOX as the CT backbone, 38.4\% FOLFIRI and 16.2\% FOLFOXIRI (Table 1).

Meanwhile, for right-sided, wt-RAS/wt-BRAFV600E MCRC, the majority $(70.7 \%)$ would offer CT + bevacizumab (53.9\% of them with FOLFOX, 31.9\% with FOLFIRI and $14.5 \%$ with FOLFOXIRI) (Table 1). Those $29.2 \%$ of oncologists who chose anti-EGFR therapy, $62.8 \%$ would offer the patient FOLFOX and 37.2\% FOLFIRI as the CT backbone (Table 1).

In the case of a mutated-RAS mCRC, most oncologists decided for FOLFOX + bevacizumab (51.9\%) while 33.3\% chose FOLFIRI + bevacizumab and $14.1 \%$ FOLFOXIRI + bevacizumab (Table 1). Two participants did not answer this specific question.

\section{Treatment choices according to years in Oncology practice, gender and time dedicated to GI cancers}

There was no statistically difference in treatment choices (CT backbone and monoclonal antibody) for left-sided or right-sided wt-RAS/wt-BRAFV600E mCRC according to years in oncology practice. However, for patients with mutated-RAS mCRC, oncologists with more than 10 years of practice preferred more FOLFOX + bevacizumab than FOLFIRI or FOLFOXIRI + bevacizumab when compared to younger oncologists $(p=0.04)$.

For left-sided, wt-RAS/wt-BRAFV600E mCRC, there was a statistically significant difference in terms of gender and treatment choices $(p=0.004)$. For instance, most female oncologists would choose FOLFOX + anti-EGFR therapy while most male oncologists would prefer FOLFIRI + anti-EGFR. For right-sided wt-RAS/wt-BRAFV600E or mutated-RAS $\mathrm{mCRC}$, there was no difference in treatment choices according to gender $(p=0.096$ and $p=0.208$, respectively).

In terms of time dedicated t o Gl practice, a statistically significant difference was seen in the right-sided wt-RAS/ wt-BRAFV600E mCRC group ( $p=0.001)$. Ninety-four percent of oncologists with more than $50 \%$ of their practice dedicated to Gl cancers would choose bevacizumab as monoclonal antibody while only $64.6 \%$ of the nonGI specialists would prefer bevacizumab. In addition, $18 \%$ of the GI specialists would choose FOLFOXIRI + bevacizumab in this scenario whereas only $7.9 \%$ of the non-Gl specialists would prefer it. For left-sided wt-RAS/wtBRAFV600E or mutated-RAS mCRC, there was no difference in treatment choices according to time dedicated to treat GI cancers ( $p=0.429$ and $p=0.433$, respectively).

Table 1. Treatment choices according to RAS/BRAF status and sidedness

\begin{tabular}{lccc}
\hline & $\begin{array}{c}\text { left-sided wt- } \\
\text { RAS/wt-BRAF }\end{array}$ & $\begin{array}{c}\text { right-sided wt- } \\
\text { RAS/wt-BRAF }\end{array}$ & mtRAS \\
\hline FOLFIRI + bevacizumab & $10(4.2 \%)$ & $54(22.6 \%)$ & $79(33.1 \%)$ \\
FOLFIRI + cetuximab/panitumumab & $105(43.9 \%)$ & $26(10.9 \%)$ & --------------- \\
FOLFOX + bevacizumab & $26(10.9 \%)$ & $91(38.1 \%)$ & $123(51.5 \%)$ \\
FOLFOX + cetuximab/panitumumab & $91(38.1 \%)$ & $44(18.4 \%)$ & ----------- \\
FOLFOXIRI + bevacizumab & $7(2.9 \%)$ & $24(10.0 \%)$ & $35(14.6 \%)$ \\
Did not answer & 0 & 0 & $2(0.8 \%)$ \\
Total & $239(100 \%)$ & $239(100 \%)$ & $239(100 \%)$ \\
\hline
\end{tabular}

\section{DISCUSSION}

Tumor sidedness and RAS/BRAF status have modified the treatment landscape of $\mathrm{mCRC}$ worldwide in the last years, although the true impact of those changes in third-world countries remains undetermined. Brazil is the $5^{\text {th }}$ largest country and presents accentuated heterogeneity which affects cancer care delivery. This is the first Brazilian survey to try to determine oncologists' first-line treatment decisions for $\mathrm{MCRC}$, according to sidedness and RAS/ $B R A F_{\text {V600F }}$ status and considering that all therapeutic choices were available in 2018.

Our study revealed interesting findings. First, it clearly showed a significant increase of women oncologists' 
proportion over time. While females corresponded to less than $10 \%$ of oncologists with more than 30 years of practice, more than half of those with less than 5 years of practice are women. These findings are in parallel with the growing presence of women in Brazilian medicine. The feminization of medicine in Brazil in the past decades has already been described. ${ }^{11}$ Such transformation may constitute a structural element of the professions evolution, with consequences in medical practices, in the quality of care and in the organization of health services. In our survey, females would prefer FOLFOX as the first-line CT backbone in $\mathrm{mCRC}$. The lower proportion of women choosing FOLFIRI could be explained by the greater probability of alopecia with this regimen when compared to FOLFOX. Probably, female physicians are less prone to indicate a treatment with hair loss potential when there is another equal effective choice with less chance of alopecia. If the proportion of women among oncologists in Brazil continue to increase, that may impact treatment preferences for $\mathrm{MCRC}$ in the future.

Other important finding was the difference in the choice of monoclonal antibody for right-sided wtRAS/Wt-BRAFV600E mCRC according to time dedicated to $\mathrm{Gl}$ cancers, where $94 \%$ of $\mathrm{Gl}$ specialists chose bevacizumab and only $64.6 \%$ of non-Gl specialists preferred bevacizumab. Several data have been accumulating over the past years showing better outcomes with bevacizumab + CT in right-sided wt-RAS/ wt-BRAFV600E $\mathrm{mCRC}$, in contrast to anti-EGFR therapy + $\mathrm{CT}$ in the left-sided wt-RAS/wt-BRAFV600E mCRC. ${ }^{6-8}$

Those answers reveal us that the more specialist an oncologist is in an area, the more in accordance with data he or she will be. The larger proportion of non-Gl specialists indicating first-line CT + anti- EGFR for rightsided wt-RAS/wt-BRAFV600E mCRC may be explained in part by lack of familiarity with current guidelines in $\mathrm{Gl}$ cancers. While the relationship between surgeon volume and outcomes has long been well established for complex cancer surgeries, the impact of oncologists' experience on outcomes for patients with metastatic tumors is unknown. ${ }^{12}$ Whether oncologists with GI specialty provide a better mCRC care remains to be determined. Furthermore, the large size of Brazil associated with its heterogeneity makes it impracticable for most oncologists to specialize in a certain area. Nonetheless, providing high-quality education among non-Gl specialists is one of the missions of Brazilian Gastrointestinal Tumors Group and may decrease disparity between $\mathrm{mCRC}$ care in the country.

Our study has several limitations. First, the questionnaire did not distinguish between academic and community-based physicians, nor did it capture whether responders worked in the public, private or both systems. We have also not captured whether the oncologist worked in outpatient clinics or hospitals, which could influence treatment choices, especially the fear of prescribing FOLFOXIRI where access to granulocyte-colony stimulating factors or hospital admissions is limited. Moreover, the real practice in terms of $\mathrm{CT}$ backbone and monoclonal antibodies' choices could not be determined as the questionnaire expected the responders to answer in a scenario where all drugs were available, which is not the case in all areas and medical services in Brazil. In addition, the extent of non-responders was not captured, which may limit the generalizability of our findings.

\section{CONCLUSION}

In conclusion, our survey indicates that tumor sidedness influences the choice of both CT backbone and monoclonal antibody in unresectable wt-RAS mCRC. In addition, oncologists' gender and percentage of time dedicated to treat GI cancers also impact therapeutic choices for $\mathrm{mCRC}$ in Brazil. We believe that the first educational task as a group is to ensure that oncologists who see patients with mCRC are practicing in accordance with literature recommendations.

\section{ACKNOWLEDGMENT}

We thank Isabele Small, who provided statistical services on behalf of SBOC (Brazilian Society of Medical Oncology).

\section{AUTHOR'S CONTRIBUTION}

Renata D'Alpino Peixoto: Collection and assembly of data, Conception and design, Data analysis and interpretation, Final approval of manuscript, Manuscript writing, Provision of study materials or patient.

Rachel P Riechelmann: Collection and assembly of data, Conception and design, Data analysis and interpretation, Final approval of manuscript, Manuscript writing, Provision of study materials or patient.
Gabriel Prolla: Collection and assembly of data, Conception and design, Data analysis and interpretation, Final approval of manuscript, Manuscript writing, Provision of study materials or patient.

Rui F. Weschenfelder: Collection and assembly of data, Conception and design, Data analysis and interpretation, Final approval of manuscript, Manuscript writing, Provision of study materials or patient. 
Gustavo dos Santos Fernandes: Collection and assembly of data, Conception and design, Data analysis and interpretation, Final approval of manuscript, Manuscript writing, Provision of study materials or patient.

Guilherme S Pereira: Collection and assembly of data, Data analysis and interpretation, Final approval of manuscript, Manuscript writing.

Maria de Lourdes de-Oliveira: Collection and assembly of data, Data analysis and interpretation, Final approval of manuscript, Manuscript writing.
Juliana F Rego: Collection and assembly of data, Data analysis and interpretation, Final approval of manuscript, Manuscript writing.

Duilio R Rocha-Filho: Collection and assembly of data, Data analysis and interpretation, Final approval of manuscript, Manuscript writing.

Anelisa K. Coutinho: Collection and assembly of data, Conception and design, Data analysis and interpretation, Final approval of manuscript, Manuscript writing, Provision of study materials or patient.

\section{REFERENCES}

1. Bray F, Ferlay J, Soerjomataram I, Siegel RL, Torre L, Jemal A. Global cancer statistics 2018: GLOBOCAN estimates of incidence and mortality worldwide for 36 cancers in 185 countries. CA Cancer J Clin. 2018 Nov;68(6):394-424. PMID: 30207593 DOI: https://doi.org/10.3322/caac.21492

2. Ministério da Saúde (BR). Instituto Nacional de Câncer - José Alencar Gomes da Silva (INCA). Estimativa 2018. Incidência de Câncer no Brasil. Rio de Janeiro (RJ): INCA; 2018. Available from: http://www1.inca. gov.br/estimativa/2018/estimativa-2018.pdf

3. Benedix F, Kube R, Meyer F, et al. Comparison of 17,641 patients with right- and left-sided colon cancer: differences in epidemiology, perioperative course, histology, and survival. Dis Colon Rectum. 2010 Jan;53(1):57-64. PMID: 20010352 DOI: https://doi.org/10.1007/DCR.0b013e3181c703a4

4. Sugai T, Habano W, Jiao YF, Tsukahara M, Takeda Y, Otsuka K, et al. Analysis of molecular alterations in left- and right-sided colorectal carcinomas reveals distinct pathways of carcinogenesis: proposal for new molecular profile of colorectal carcinomas. J Mol Diagn. 2006 May;8(2):193-201. DOI: https://doi.org/10.2353/jmoldx.2006.050052

5. Cancer Genome Atlas Network. Comprehensive molecular characterization of human colon and rectal cancer. Nature. 2012 Jul;487(7407):330-7. PMID: 22810696 DOI: https://doi.org/10.1038/ nature11252

6. 6. Stintzing S, Modest DP, Rossius L, et al. FOLFIRI plus cetuximab versus FOLFIRI plus bevacizumab for metastatic colorectal cancer (FIRE3): a post-hoc analysis of tumour dynamics in the final RAS wild-type subgroup of this randomised open-label phase 3 trial. Lancet Oncol. 2016 Oct;17(10):1426-34. DOI: https://doi. org/10.1016/S1470-2045(16)30269-8

7. Venook $\mathrm{AP}$, Ou FS, Lenz $\mathrm{HJ}$, et al. Primary $\left(1^{\circ}\right)$ tumor location as an independent prognostic marker from molecular features for overall survival (OS) in patients (pts) with metastatic colorectal cancer (mCRC): analysis of CALGB/SWOG 80405 (Alliance). J Clin Oncol. 2017 May;35(Suppl 15):3503. DOI: https://doi.org/10.1200/ JCO.2017.35.15_suppl.3503

8. Tejpar S, Stintzing S, Ciardiello F, et al. Prognostic and predictive relevance of primary tumor location in patients with RAS wild-type metastatic colorectal cancer: retrospective analyses of the CRYSTAL and FIRE-3 trials. JAMA Oncol. 2017 Feb;3(2):194-201. DOI: https://doi.org/10.1001/ jamaoncol.2016.3797

9. National Comprehensive Cancer Network (NCCN). Clinical Practice Guidelines in Oncology. Colon Cancer. Plymouth: NCCN; 2018. Available from: https://www.ncen.org/professionals/physician_gls/pdf/colon.pdf

10. Yoshino $T$, Arnold $D$, Taniguchi $H$, et al. PanAsian adapted ESMO consensus guidelines for the management of patients with metastatic colorectal cancer: a JSMO- ESMO initiative endorsed by CSCO, KACO, MOS, SSO and TOS. Ann Oncol. 2018 Jan;29(1):44-70. DOI: https://doi. org/10.1093/annonc/mdx738

11. Scheffer MC, Cassenote AJF. The feminization of Medicine in Brazil. Rev Bioét. 2013 Aug;21(2):268-77. DOI: https://doi.org/10.1590/ S1983-80422013000200010

12. Luft HS, Bunker JP, Enthoven AC. Should operations be regionalized? The empirical relation between surgical volume and mortality. N Engl J Med. 1979 Dec;301(25):1364-9. PMID: 503167 DOI: https://doi.org/10.1056/ NEJM197912203012503 